\title{
The role of graphene coating on cordierite-supported Pd monolithic catalysts for low-temperature combustion of toluene
}

\author{
Wen Li, Hongqi Ye, Gonggang Liu, Hongchao Ji, Yonghua Zhou *, Kai Han \# \\ State Key Laboratory for Powder Metallurgy, College of Chemistry and Chemical Engineering, Central South University, Changsha 410083, Hunan, China
}

\section{A R T I C L E I N F O}

\section{Article history:}

Received 13 November 2017

Accepted 20 December 2017

Published 5 May 2018

\section{Keywords:}

Graphene coating

Palladium

Catalytic combustion

Steam

Adsorption

\begin{abstract}
A B S T R A C T
In the present work, a Pd/graphene/cordierite (Pd/Gr/Cor) composite was prepared as a monolithic catalyst for low-temperature combustion of toluene. We mainly focused on understanding the role of graphene coating through investigation of catalytic performance and adsorption behavior of the composite. Compared with the traditional Pd/Cor catalyst without graphene coating, Pd/Gr/Cor catalyst delivered much higher activity and stability for toluene catalytic combustion in both dry and moist conditions. Transmission electron microscopy (TEM) and hydrophobic characterizations indicated that graphene coating can considerably improve the dispersity of Pd nanoparticles and enhance the hydrophobicity of the cordierite support. The adsorption behavior of the above two catalysts, including adsorption isothermal, adsorption kinetics, and adsorption thermodynamics were carefully investigated. The simulation results indicated that a large amount of toluene was adsorbed on graphene surface through relatively weak interaction, whereas only a relatively small amount of toluene was adsorbed on Pd surface with strong affinity. The adsorption thermal calculation indicated that the adsorption of toluene on graphene was a process with reduced entropy, indicating highly-ordered assembly of toluene molecular on graphene. It is the significant concentration and affinity gap between graphene and Pd that ensures a simultaneously and rapid transfer of toluene during the reaction process.
\end{abstract}

(C) 2018, Dalian Institute of Chemical Physics, Chinese Academy of Sciences. Published by Elsevier B.V. All rights reserved.

\section{Introduction}

Catalytic combustion is one of the most important technologies for eliminating volatile organic compounds (VOCs) pollutants [1,2]. The development of high-performance monolithic catalyst has been viewed as a promising research direction to achieve effective removal of VOCs by catalytic combustion, owing to the catalyst's low pressure drop, mass transfer enhancement, ease to scale-up and separation regeneration $[3,4]$. However, the surface area of most traditional monolithic catalyst supports, e.g., cordierite is relatively low, thus making them always required modification with activated alumina or other high-specific-surface coatings [5,6]. As for active catalyst components, noble metals such as $\mathrm{Pd}$ and $\mathrm{Pt}$ have been known as highly effective catalysts [7]. The dispersity and particle size of the noble metals are two key factors. The particles with high dispersity and uniform size distribution could not only enhance the catalytic combustion activity but also reduce the used amount of noble metals to minimize the cost. Besides, since the catalyst particles are closely interrelated to the coating of catalyst supports, the catalytic activity is normally affected also by the surface properties of coating layers as well as interactions

\footnotetext{
* Corresponding author. Tel/Fax: +86-731-88879616; E-mail: zhouyonghua@csu.edu.cn

\# Corresponding author. Tel/Fax: +86-731-88879616; E-mail:hankai@csu.edu.cn

This work was supported by the National Natural Science Foundation of China $(21276284,21676303,21706292)$.

DOI: 10.1016/S1872-2067(18)63015-3 | http://www.sciencedirect.com/science/journal/18722067 | Chin. J. Catal., Vol. 39, No. 5, May 2018
} 
between the coating and noble metals $[8,9]$. The other challenge is the water vapor resulting from combustion reaction and the VOC feed, which can be easily adsorbed on the hydrophilic oxide surface and thus significantly reduce the catalytic activity of the noble metal catalysts $[10,11]$. Therefore, choosing an appropriate coating layer is vital for developing highly active noble-metal monolithic catalysts for VOC elimination.

To improve the moisture resistance of the catalyst, hydrophobic active carbon, carbon nano-fiber and other carbon materials have been explored as catalyst support for low-temperature catalytic combustion [12,13]. Zhang and coworkers [14] compared toluene catalytic combustion activity of the Pt catalyst supported on activated carbon and alumina. When the reaction was carried out in the wet gas stream at 130 ${ }^{\circ} \mathrm{C}$, the activity of alumina-supported catalyst fell by $67 \%$, while the activated carbon dropped by only $14 \%$ compared with dry conditions. Graphene is an extensively explored carbon material as a catalyst support because of its large specific surface area and high chemical stability $[15,16]$. Furthermore, our previous studies revealed that graphene nanosheets can be firmly immobilized on the surface of cordierite by hydrogen bonding or electrostatic adsorption. In addition, Pd nanoparticles loaded on the graphene exhibited high dispersity and a uniform size of less than $5 \mathrm{~nm}$. The prepared catalyst exhibited excellent catalytic performance and stability in hydrogenation reactions [17, 18]. However, the role or the mechanism of graphene coating layers in the monolithic catalysts was unknown in our previous work $[17,18]$. In the present work, we mainly focused on understanding the role of graphene coating through investigation of catalytic performance and adsorption behavior of $\mathrm{Pd} / \mathrm{Cor}$ and $\mathrm{Pd} / \mathrm{Gr} /$ Cor catalysts. The catalytic performance for the two catalysts were studied in both dry and moist conditions. Additionally, as graphene with a perfect $s p^{2}$ hybridization of carbon atoms may absorb benzene series with benzene ring structure due to the $\pi-\pi$ bonding effect [19], it is very beneficial to remove low concentrations of VOCs by amplifying the adsorption-catalytic synergistic effect. The graphene coating layer is demonstrated to play important roles in enhancing the dispersion of noble-metal particles, thus improving the hydrophobicity of catalyst support and endowing the catalyst with excellent adsorption for benzene series. As a result, the $\mathrm{Pd} / \mathrm{Gr} / \mathrm{Cor}$ catalyst exhibited high performance for catalytic combustion of toluene.

\section{Experimental}

\subsection{Raw material}

Cordierite, from Jiangxi Xingfeng Chemical Packing Company, and $\mathrm{PdCl}_{2}$ with a $\mathrm{Pd}$ content of $60 \%$, from Shaanxi Kaida Chemical Ltd, were purchased. The $\mathrm{H}_{2} \mathrm{PdCl}_{4}$ aqueous solution ( $0.01 \mathrm{~mol} / \mathrm{L})$ was used in the present work and prepared by

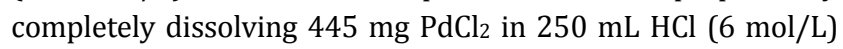
aqueous solution.

\subsection{Catalyst preparation}

Graphene oxide was prepared using the modified Hummers method, and Pd/Gr/Cor was prepared by ultrasonic impregnation techniques, as demonstrated in our previous work [18]. By contrast, the cordierite was immersed in the $\mathrm{H}_{2} \mathrm{PdCl}_{4}$ aqueous solution by ultrasound for $20 \mathrm{~min}$, dried at $60{ }^{\circ} \mathrm{C}$ for $6 \mathrm{~h}$, calcined in air at $350^{\circ} \mathrm{C}$ for $2 \mathrm{~h}$ and then followed by reduction in a potassium borohydride $\left(\mathrm{KBH}_{4}\right)$ solution, the resulting catalyst is denoted as $\mathrm{Pd} /$ cordierite (Pd/Cor). The loading of $\mathrm{Pd}$ in $\mathrm{Pd} / \mathrm{Gr} /$ Cor was $0.08 \%$ by ICP measurement and the loading of $\mathrm{Pd}$ in the Pd/Cor catalyst was controlled at a similar level.

\subsection{Catalyst characterization}

The morphology and size of palladium particles on monolithic catalysts were recorded by transmission electron microscopy (TEM) on a JEOL JEM-2100 (Japan) operated at 200 $\mathrm{kV}$. X-ray diffraction (XRD) measurement of monolithic catalyst was carried out on a 3014-Z2 diffractometer (Japan) with a $\mathrm{Cu}$ $\mathrm{K} \alpha$ radiation at a scanning rate of $5 \% \mathrm{~min}$. The Brunauer-Emmett-Teller (BET) surface area of monolithic catalysts was calculated by the BET model at pressure ranging from 0.005 to $0.02 \mathrm{MPa}$ on an Autosorb-iQ (Quantachrome) analyzer at $-196{ }^{\circ} \mathrm{C}$. The contact angle measurements were recorded on contact angle tester JC2000D1.

\subsection{Toluene catalytic combustion reaction experiments}

Catalytic performance of the monolithic catalysts was tested through catalytic combustion of toluene. The catalytic reaction was carried out in a tubular reactor. Toluene was carried by nitrogen spurge, mixed with air in a mixer, and then transferred into the reactor for reaction. The toluene concentration and airspeed can be changed by adjusting the flow rate of nitrogen and air. The reaction was monitored by gas chromatographic analysis (SHIMADZU 2010 plus, column RTX-5 with an inner diameter of $0.25 \mathrm{~mm}$, a film depth of $0.25 \mu \mathrm{m}$ and a length of $30 \mathrm{~m}$ ) of the toluene outlet concentration withdrawn from the reactor.

Stability tests for the catalyst in moisture were as follows: water vapor was carried by bubbling air, mixed with toluene carried by nitrogen gas, and then carried out of the reaction. The conditions were as follows: toluene concentration $=15$ $\mathrm{g} / \mathrm{m}^{3}$, relative humidity $=81 \%$, space velocity $=4000 \mathrm{~h}^{-1}$, the reaction temperature $=220^{\circ} \mathrm{C}$.

\subsection{Toluene adsorption experiments}

Toluene adsorption experiments were carried out through a similar process to that of the toluene catalytic combustion reaction. At the same temperature, the breakthrough curve would be drawn by detecting the outlet concentration of toluene. The simulations were further conducted based on the tested data.

\section{Results and discussion}

\subsection{Characterization of catalysts}




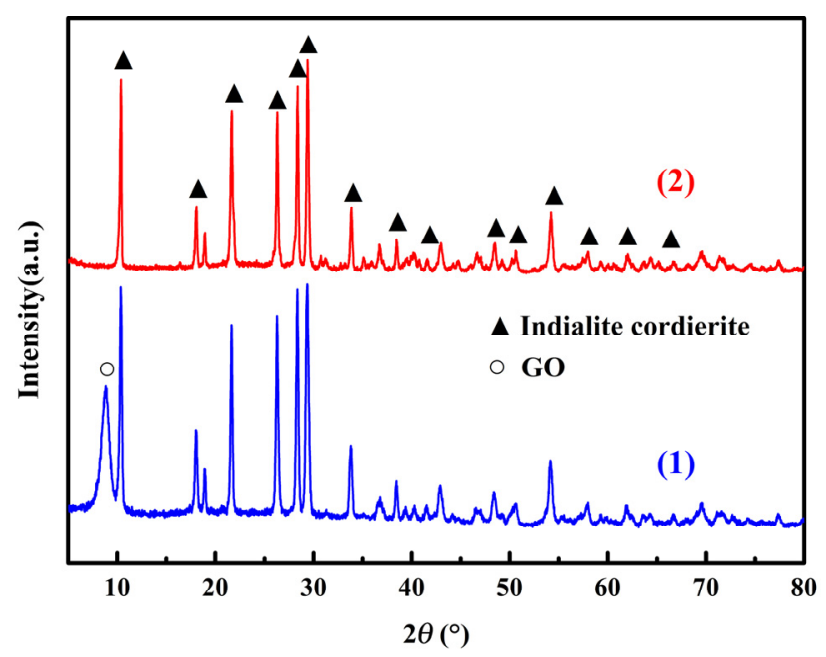

Fig. 1. XRD patterns of the Pd/Gr/Cor catalyst before (1) and after (2) reduction.

The XRD patterns of the Pd/Gr/Cor catalyst before and after reduction are shown in Fig. 1. Before reduction of the $\mathrm{Pd} / \mathrm{Gr} /$ Cor catalyst, the characteristic peak of graphene oxide (GO) $\left(2 \theta=9^{\circ}\right)$ can be clearly observed (Fig. 1(1)). It indicates that graphene oxide sheets have successfully been coated on the surface of the cordierite. After reduction, peaks of graphene oxide disappeared, implying the transformation of graphene oxide to graphene. However, characteristic graphene peaks at $2 \theta=26^{\circ}$ could not be observed in XRD pattern of Pd/Gr/Cor catalyst after reduction (Fig. 1(2)), which is probably due to the interference of cordierite [20]. TEM images of $\mathrm{Pd} /$ Cor and $\mathrm{Pd} / \mathrm{Gr} /$ Cor catalysts are provided in Fig. 2. The Pd particle size was reduced, and the particles dispersed more uniformly in presence of graphene coating. The contact angle measurement was further performed to evaluate their hydrophilicities, and the results are shown in Fig. S1. The results indicate that the introduction of graphene coating could greatly increase the hydrophobicity of the Pd/Cor catalyst.

\subsection{Toluene catalytic combustion performance on the Pd/Cor and $\mathrm{Pd} / \mathrm{Gr} /$ Cor catalysts}

The activities in dry and wet conditions and the stability of $\mathrm{Pd} /$ Cor and $\mathrm{Pd} / \mathrm{Gr} /$ Cor catalysts in wet condition are illustrated in Fig. 3. As illustrated in Fig. 3(a), compared with the $\mathrm{Pd} /$ Cor catalyst, the toluene ignition temperature (conversion
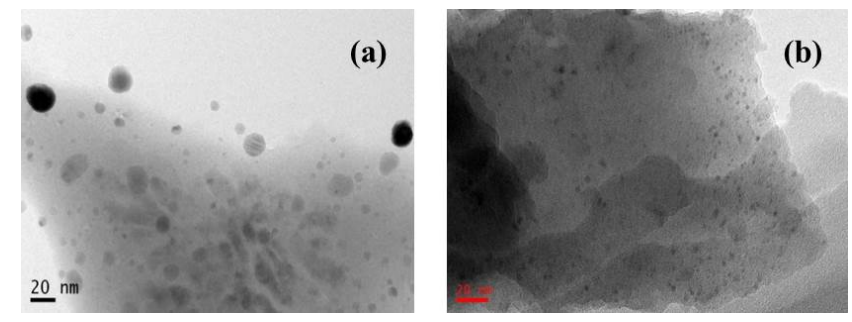

Fig. 2. TEM images of the $\mathrm{Pd} / \operatorname{Cor}(\mathrm{a})$ and $\mathrm{Pd} / \mathrm{Gr} / \mathrm{Cor}$ (b) catalysts.

rate $=10 \%$ ) of the $\mathrm{Pd} / \mathrm{Gr} /$ Cor catalyst was decreased by $43{ }^{\circ} \mathrm{C}$ (from 175 to $132{ }^{\circ} \mathrm{C}$ ), and complete combustion temperature (conversion rate $=99 \%$ ) was decreased by $40{ }^{\circ} \mathrm{C}$ (from 300 to $260{ }^{\circ} \mathrm{C}$ ). It is obvious that the presence of graphene coating promoted the activity of the $\mathrm{Pd}$ catalyst in toluene catalytic combustion in the dry condition.

To investigate the moisture resistance of the catalysts, the toluene catalytic combustion on $\mathrm{Pd} / \mathrm{Cor}$ and $\mathrm{Pd} / \mathrm{Gr} /$ Cor were carried out in relative humidity of $81 \%$, as illustrated in Fig. 3(b). It was observed that steam has no effect on the toluene ignition temperature on the $\mathrm{Pd} / \mathrm{Cor}$ and $\mathrm{Pd} / \mathrm{Gr} /$ Cor catalysts, but it causes the increase of the complete combustion temperature of the two catalysts (from 300 to $430{ }^{\circ} \mathrm{C}$ on $\mathrm{Pd} /$ Cor and from 260 to $360{ }^{\circ} \mathrm{C}$ on $\mathrm{Pd} / \mathrm{Gr} / \mathrm{Cor}$ ). Furthermore, stabilities of the $\mathrm{Pd} /$ Cor and $\mathrm{Pd} / \mathrm{Gr} /$ Cor catalysts for toluene catalytic combustion in relative humidity of $81 \%$ are illustrated in Fig. 3(c). We can observe that the activity of $\mathrm{Pd} /$ Cor decreased gradually in moist feed, whereas the $\mathrm{Pd} / \mathrm{Gr} /$ Cor catalyst exhibits better stability. To further demonstrate the stability difference, TEM characterizations of used Pd/Cor and Pd/Gr/Cor catalysts under wet condition were performed as illustrated in Fig. S2. The used $\mathrm{Pd} / \mathrm{Gr} /$ Cor catalyst exhibits unchanged Pd particle size and dispersity on the support compared with TEM images of the fresh catalysts in Fig. 2, while the average particle size of Pd on the used $\mathrm{Pd} /$ Cor catalyst without the graphene coating layer exhibits a slight increase with the presence of much more Pd particles about $20 \mathrm{~nm}$. These results directly indicate the stability difference between the $\mathrm{Pd} /$ Cor and $\mathrm{Pd} / \mathrm{Gr} /$ Cor catalysts and that the graphene coating layer plays an important role in improving the catalysts' stability especially under the moisture condition. This may be due to the hydrophobicity of the graphene coating, which inhibited the adsorption of water molecules, thus impelling the catalytic combustion to proceed. By contrast, the graphene coating may effectively anchor Pd parti-
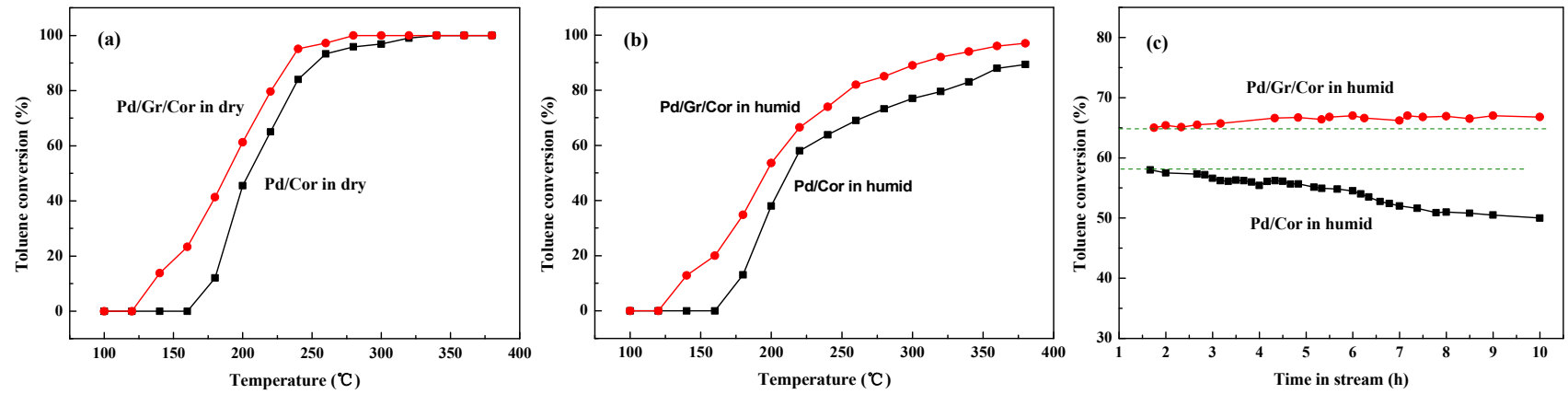

Fig. 3. Activities of the Pd/Cor and Pd/Gr/Cor catalysts in dry (a) and wet (b) toluene as well as the stability of the Pd/Cor and Pd/Gr/Cor catalysts in wet toluene $(\mathrm{c})$. 
cles,thus preventing their agglomeration and deactivation. Therefore, the stability of the catalyst could be further improved.

It is worth pointing out that although the graphene cover can enhance the hydrophobicity of the catalyst, the surface is still not absolutely hydrophobic. This means that unlike in the dry condition, aspects of catalytic performance such as complete combustion temperature still can be affected in the wet condition. However, the $\mathrm{Pd} / \mathrm{Gr} /$ Cor catalyst exhibits much better catalytic performance, especially in terms of stability (Fig. 3(b) and 3(c)), than the Pd/Cor catalyst does under the wet condition. This implies the important role of the graphene cover.

The activities of the $\mathrm{Pd} / \mathrm{Gr} / \mathrm{Cor}$ catalyst under different space velocities were further studied, as illustrated in Fig. 4(a). With the increase of the space velocity, the residue time of toluene decreases, therefore, the toluene conversion rate decreases. The catalytic combustion of toluene on the supported Pd catalyst can be normally described by Eley-Rideal mechanism [21,22]. According to this mechanism, oxygen is dissociated on Pd particles and further reacts with the toluene molecule in bulk gas, and the reaction kinetics confirms the first-order reaction law as formula (1):

$$
-\ln (1-x)=k t
$$

where $x, k$ and $t$ represent the toluene conversion rate, the reaction rate constant in $1 / \mathrm{s}$ and the reaction time in $\mathrm{s}$, respectively. The modeling results are illustrated in Fig. 4(b). The linear correlation coefficient $R^{2}$ in the range of 0.990-0.999, suggesting that toluene combustion on the $\mathrm{Pd} / \mathrm{Gr} /$ Cor catalyst obeys the first-order reaction law. According to the Arrhenius equation, $\ln k \sim 1 / T$, the linear fitting result with a linear correlation coefficient $R^{2}=0.995$ in Fig. 4(c) gives an activation energy of $60.93 \mathrm{~kJ} / \mathrm{mol}$ on the $\mathrm{Pd} / \mathrm{Gr} /$ Cor catalyst. This value is lower than that of reported data for the Pd/ZSM catalyst (106.1 $\mathrm{kJ} / \mathrm{mol}$ ), which produced very similar catalytic activity to that of the Pd/Cor catalyst [23], indicating much higher catalytic activity of the $\mathrm{Pd} / \mathrm{Gr} /$ Cor catalyst for toluene catalytic combustion than the most used Pd/ZSM and Pd/Cor catalysts.

\subsection{Toluene adsorption performance on the Pd/Cor and $\mathrm{Pd} / \mathrm{Gr} /$ Cor catalysts and modelling}

To understand adsorption performances of toluene on dif-

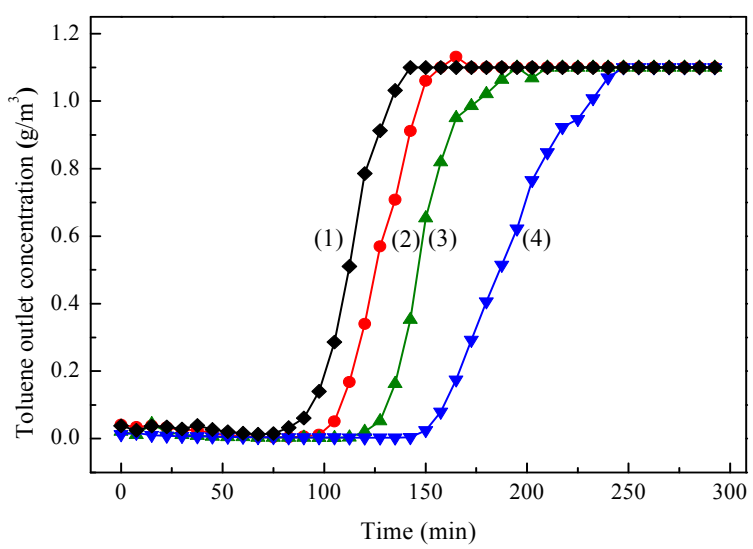

Fig. 5. The breakthrough curve of toluene on Pd/Cor (1), Cor (2), $\mathrm{Gr} /$ Cor (3) and Pd/Gr/Cor (4) (The tests were performed at temperature of $30{ }^{\circ} \mathrm{C}$ and toluene concentration of $1.1 \mathrm{~g} / \mathrm{m}^{3}$ ).

ferent catalysts, the breakthrough curves of toluene on Pd/Cor and $\mathrm{Pd} / \mathrm{Gr} / \mathrm{Cor}$ under the same condition were plotted as illustrated in Fig. 5. The saturation adsorption capacity of toluene on the specific catalyst can be obtained by integrating the breakthrough curve between the beginning point and the complete penetration point. The penetration time of $\mathrm{Pd} / \mathrm{Gr} / \mathrm{Cor}$ was found to be longer and exhibits a larger saturation adsorption capacity $(22.66 \mathrm{mg} / \mathrm{g})$ than that of $\mathrm{Pd} /$ Cor $(13.22 \mathrm{mg} / \mathrm{g})$. The pore structure of the support and the Pd particle size have a significant effect on the adsorption of the gas molecule. The contrast of the pore structure and the Pd particle size of Pd/ Cor and Pd/Gr/Cor is presented in Table S1.

The graphene coating only slightly decreases the BET surface area of cordierite and promotes slightly the dispersion of Pd. Without considering the effect of the differences in pore structure and the Pd size, the enhanced adsorption saturation of toluene on $\mathrm{Pd} / \mathrm{Gr} /$ Cor could be attributed to the graphene coating. To demonstrate how the graphene coating enhances the adsorption of toluene, the adsorption isotherm of toluene on $\mathrm{Pd} / \mathrm{Gr} / \mathrm{Cor}$ and modelling were studied as illustrated in Fig. 6. In the figure, the adsorption capacity and adsorption rate along with the pressure changes greatly when the pressure is relatively low, indicating that the toluene has a rapid adsorption on the $\mathrm{Pd} / \mathrm{Gr} /$ Cor catalyst due to flat structure of the graphene coating. The isotherms were fitted by Langmuir and
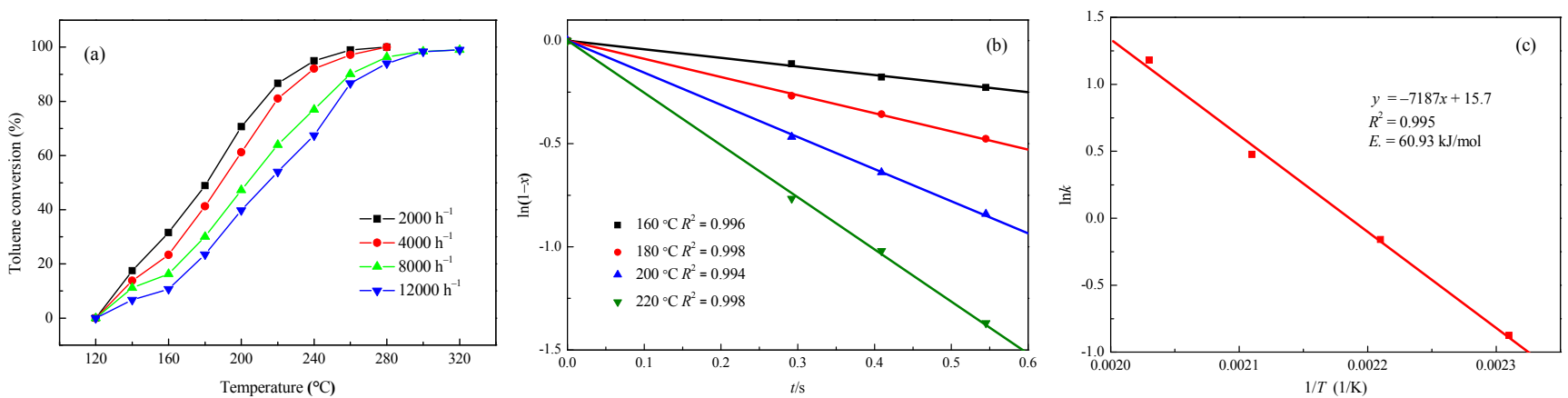

Fig. 4. (a) The effect of space velocity on the activity of the Pd/Gr/Cor catalyst; (b) First-order reaction kinetics modelling; (c) The activation energy result (at space velocity of $4000 \mathrm{~h}^{-1}$ ). 


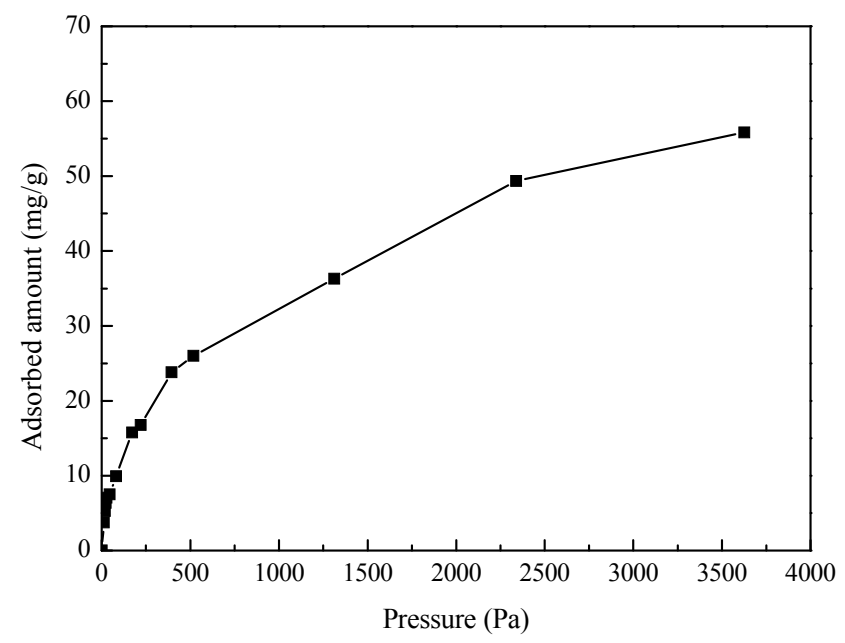

Fig. 6. The adsorption isotherm of toluene on $\mathrm{Pd} / \mathrm{Gr} /$ Cor at $40{ }^{\circ} \mathrm{C}$.

Freundlich models, respectively, as illustrated in Fig. 7. The Langmuir isotherm equation is as follows:

$$
\begin{aligned}
q & =q_{\mathrm{m}} \mathrm{bp} /(1+\mathrm{bp}) \\
1 / q & =1 / q \mathrm{~m}+1 / q_{\mathrm{mb}} \times 1 / p
\end{aligned}
$$

The Freundlich isotherm equation is as follows:

$$
\begin{aligned}
q & =K \mathrm{p}^{n} \\
\log q & =n \log C+\log K
\end{aligned}
$$

The correlation coefficients of the Langmuir model and the Freundlich model are 0.94916 and 0.99241 , respectively. Results indicated that toluene adsorption on the Pd/Gr/Cor catalyst fitted with the Freundlich adsorption model better. For the Freundlich adsorption model, the chemical adsorption, which is a strong adsorption [27], was more likely in existence.

To further explore the roles of Pd particles and the graphene coating on toluene adsorption, the localized adsorption isotherm models for two sites was applied in the current study $[28,29]$. If we assume the adsorption of toluene on both Pd and graphene according to the Langmuir model, then the two sites' localized Langmuir isotherm equation ( $\mathrm{L} 2 \mathrm{~m})$ can be written as

$$
q=q_{m}\left[\frac{(1-f) K_{a} p}{1+K_{a} p}+\frac{f K_{m} p}{1+K_{m} p}\right]
$$

Where $p$ is the equilibrium pressure, $q$ is the number of adsorbed moles, $q_{m}$ is the maximum adsorbed amount, $f$ is the fraction of the adsorbed amount, and $K_{a}$ and $K_{m}$ are adsorption constants for the catalytic support and the Pd particles, respectively. Parameters such as $q_{m}, K_{a}$ and $K_{m}$ are temperature dependent.

So, if we assume the adsorption of toluene on Pd and graphene according to the Langmuir and Freundlich model, respectively, the two sites' localized Freundlich and Langmuir combined isotherm equation (FLm) can be written as

$$
q=(1-f) K_{a} p^{n 1}+q_{m} \frac{f K_{m} p}{1+K_{m} p}
$$

The two sites' localized Langmuir isotherm model (L2m) is illustrated in Fig. 8(a), and the two sites' localized Freundlich and Langmuir combined isotherm model (FLm) is illustrated in Fig. 8(b).

Because of the high free degree of the FLm model $\left(K_{m}, K_{a}, n\right)$, we cannot get the simulating result by directly using FLm. Furthermore, the correlating efficient using the L2m model for all pressure range is only 0.9544 . Considering the stronger applicability and generality of $\mathrm{L} 2 \mathrm{~m}$ at lower pressure, the modeling result of the L2m model for the $\mathrm{Pd} / \mathrm{Gr} /$ Cor catalyst at 0-500 $\mathrm{Pa}$ is illustrated in Fig. 8(a). As expected, the L2m model was satisfactorily correlated with the adsorption data at 0-500 $\mathrm{Pa}$. The red dotted lines, which represent the adsorption capacities of toluene on the Pd particles, are sharply increased at relatively lower pressures, and they then approached a horizontal plateau. This result is similar to that reported in the literature [28], and it can be applied to higher pressure. As illustrated in Fig. 8(b), the FLm model was more satisfactorily correlated with the adsorption data for all pressure range than the $\mathrm{L} 2 \mathrm{~m}$ model. The adsorption amounts of toluene on graphene (blue dotted line) gradually increased with pressure and they fitted the Freundlich model. This indicated that there was a $\pi-\pi$ conjugation effect between toluene molecule and the graphene carbon ring, resulting in a strong adsorption effect of $\mathrm{Pd} / \mathrm{Gr} /$ Cor for toluene [30-32]. The contrast of red and blue dotted line in Fig. 8(b) indicates that graphene has a higher adsorption capacity for toluene than that of Pd particles. However, the estimated values of adsorption equilibrium coefficient $K_{m}$ are greater than those of $K_{a}$, suggesting that Pd particles have stronger adsorption affinity to toluene than that of graphene.

Meanwhile, the toluene adsorption kinetics on the
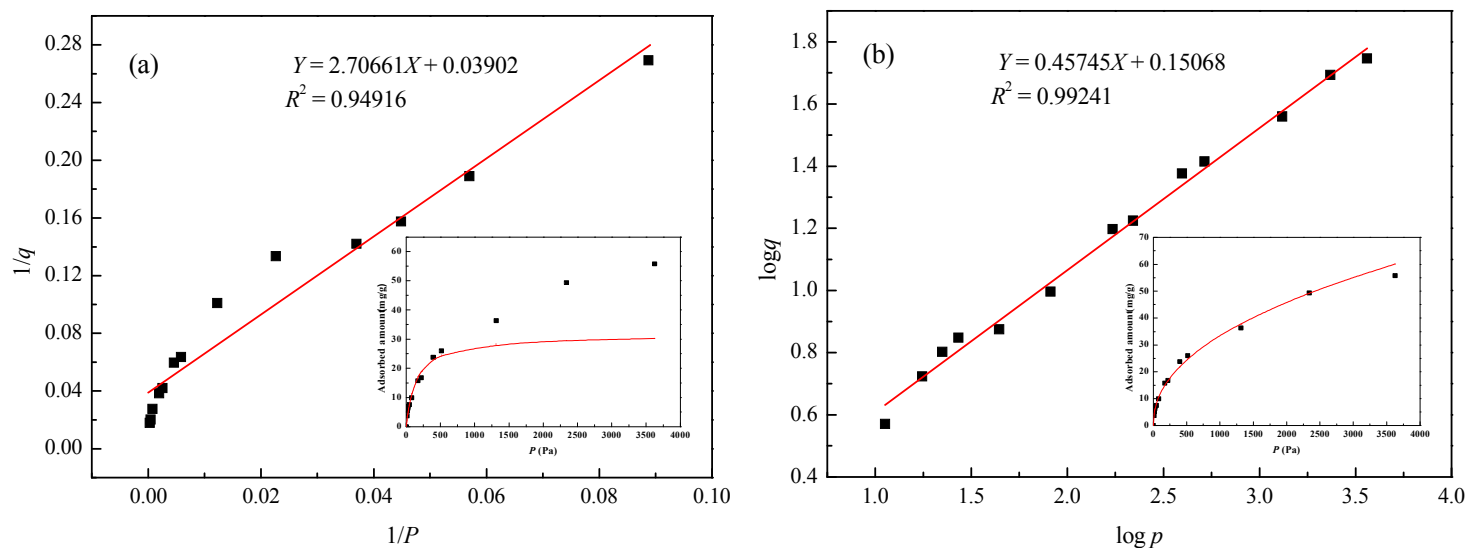

Fig. 7. Langmuir (a) and Freundlich (b) fitting for toluene adsorption on $\mathrm{Pd} / \mathrm{Gr} / \mathrm{Cor}$ at $40{ }^{\circ} \mathrm{C}$. 

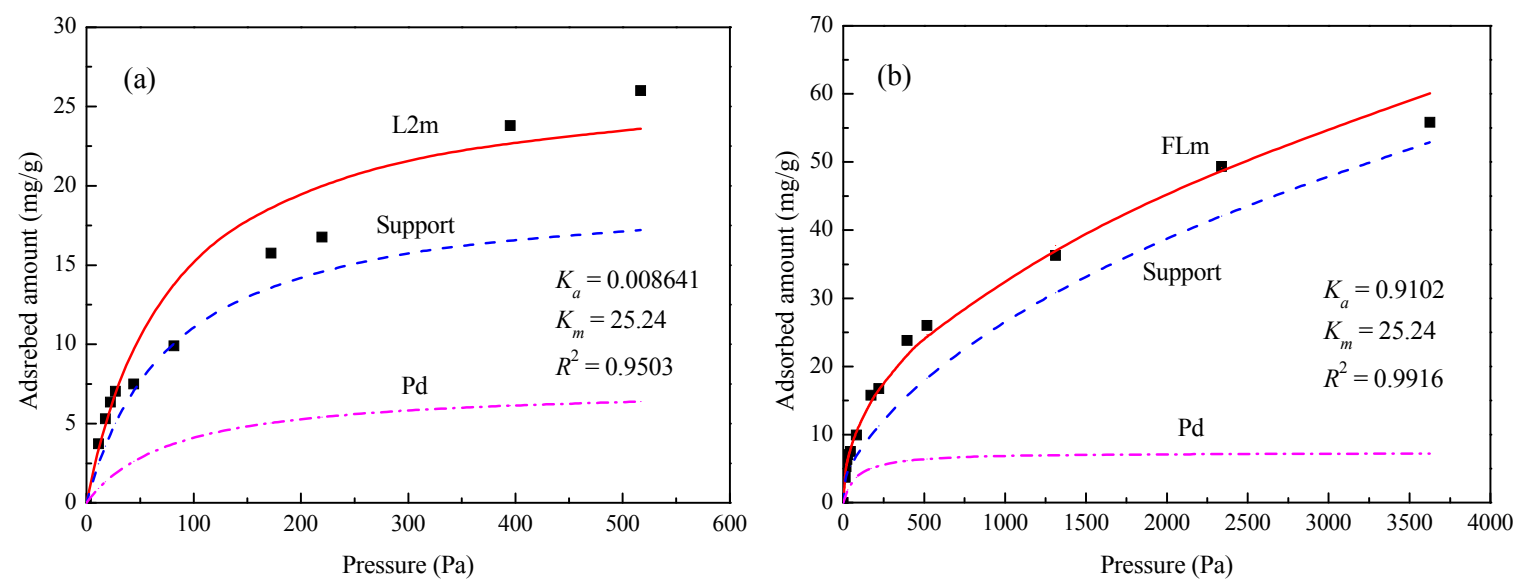

Fig. 8. (a) The two sites' localized Langmuir isotherm model (L2m) for toluene adsorption on Pd/Gr/Cor at $40{ }^{\circ} \mathrm{C}$ and (b) the two sites' localized Freundlich and Langmuir combined isotherm model (FLm) for toluene adsorption on $\mathrm{Pd} / \mathrm{Gr} / \mathrm{Cor}$ at $40{ }^{\circ} \mathrm{C}$.

$\mathrm{Pd} / \mathrm{Gr} /$ Cor catalyst was studied to better understand the adsorption behavior. Breakthrough curves of toluene at different temperatures and different concentrations are provided in Fig. 9(a) and Fig. S3(a). Then, the adsorption kinetics can be obtained from the breakthrough curve as illustrated in Fig. 9(b) and Fig. S3(b). It reveals that the adsorption rate of toluene on the $\mathrm{Pd} / \mathrm{Gr} /$ Cor catalyst at the period of low coverage rate is independent of the concentration. The adsorption rate of toluene is higher than the surface reaction rate on Pd particles. In addition, when toluene is combusted on the Pd catalyst, the graphene cover could simultaneously and rapidly transfer toluene to Pd particles due to the significant concentration and affinity gap.

Furthermore, the toluene adsorption thermodynamics on $\mathrm{Pd} / \mathrm{Gr} /$ Cor catalyst was studied. The Clausius-Clapeyron equation is often used for calculating the isosteric heat of adsorption, which depends on the monolayer adsorption model [33, 34]. The detail calculation procedure is described in the Supporting Information. The isosteric heat of adsorption of toluene on $\mathrm{Pd} / \mathrm{Gr} /$ Cor catalyst was calculated to be $Q_{\mathrm{st}}=91.54 \mathrm{~kJ} / \mathrm{mol}$ at $T_{1}=20{ }^{\circ} \mathrm{C}, P_{1}=27.0924 \mathrm{~Pa}, T_{2}=40{ }^{\circ} \mathrm{C}, P_{2}=298.3044 \mathrm{~Pa}, q=$ $18.18488 \mathrm{mg} / \mathrm{g}$. Adsorption heat increases will with the decrease of the adsorption capacity, and adsorption becomes
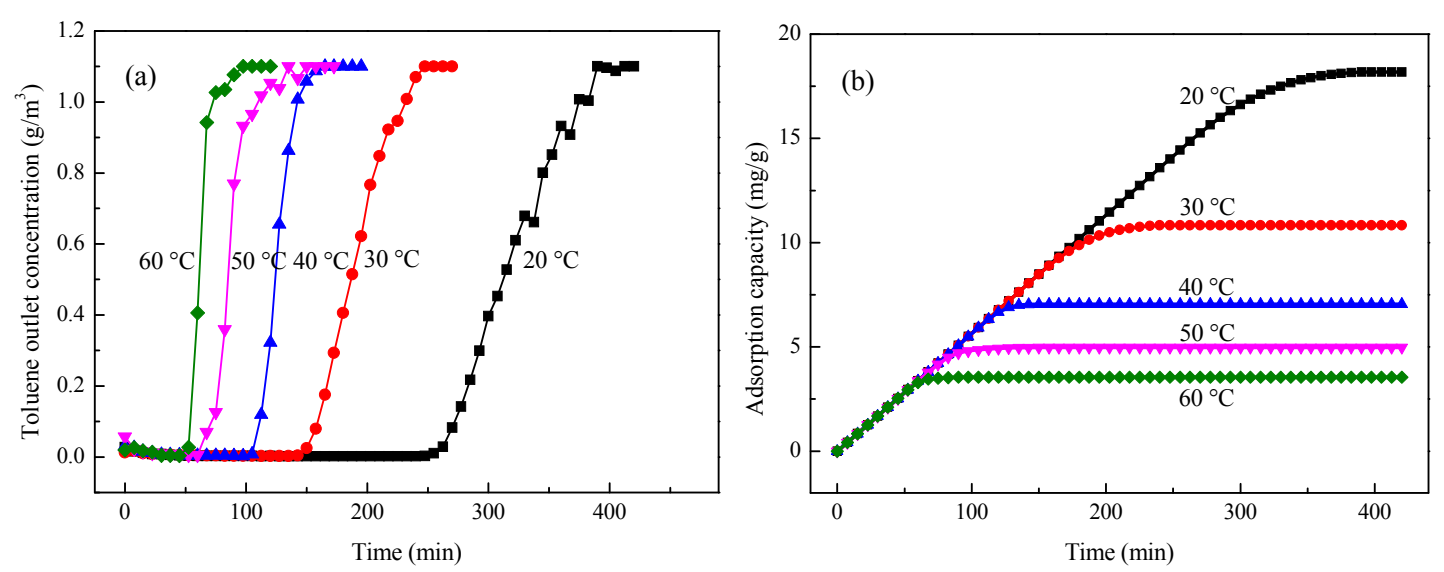

Fig. 9. (a) The breakthrough curve of toluene on Pd/Gr/Cor at different temperatures; (b) The dynamic curve of toluene on Pd/Gr/Cor at different temperatures. easier. It can be observed that the adsorption heat of toluene on the $\mathrm{Pd} / \mathrm{Gr} /$ Cor catalyst is close to the heat of chemical reaction, indicating the nature of chemisorption.

The isosteric enthalpy $\Delta \mathrm{H}$ can be estimated by the Clausius-Clapeyron equation $[1,2]$

$$
\ln C=\Delta H / \mathrm{R} T+K
$$

As for $\mathrm{Pd} / \mathrm{Gr} /$ Cor, $\Delta H$ is calculated to be $\Delta H=-91.45 \mathrm{~kJ} / \mathrm{mol}$ $<0$, indicating that the adsorption of toluene on the $\mathrm{Pd} / \mathrm{Gr} / \mathrm{Cor}$ catalyst is an exothermic reaction. In addition, the smaller the adsorption capacity is, the smaller the isosteric adsorption enthalpy $\Delta H$ is.

The adsorption free energy $\Delta G$ can be calculated by the following formula [3]

$$
\Delta G=R T \ln \left(p / p_{0}\right)
$$

When the adsorption temperature is $40^{\circ} \mathrm{C}$, the relationship between $\Delta G$ and adsorption capacity as illustrated in Fig. 10, $\Delta G$ is negative, and the adsorption of toluene on the $\mathrm{Pd} / \mathrm{Gr} / \mathrm{Cor}$ catalyst proceeds spontaneously.

The adsorption entropy $\Delta S$ can be calculated by the Gibbs Helmholtz equation [3]

$$
\Delta S=(\Delta H-\Delta G) / T
$$

Given $\Delta H=-91.45 \mathrm{~kJ} / \mathrm{mol}, \Delta S=-0.2633 \mathrm{~kJ} / \mathrm{mol}<0$ (Table 1). The negative $\Delta S$ reveals that the adsorption of toluene on 


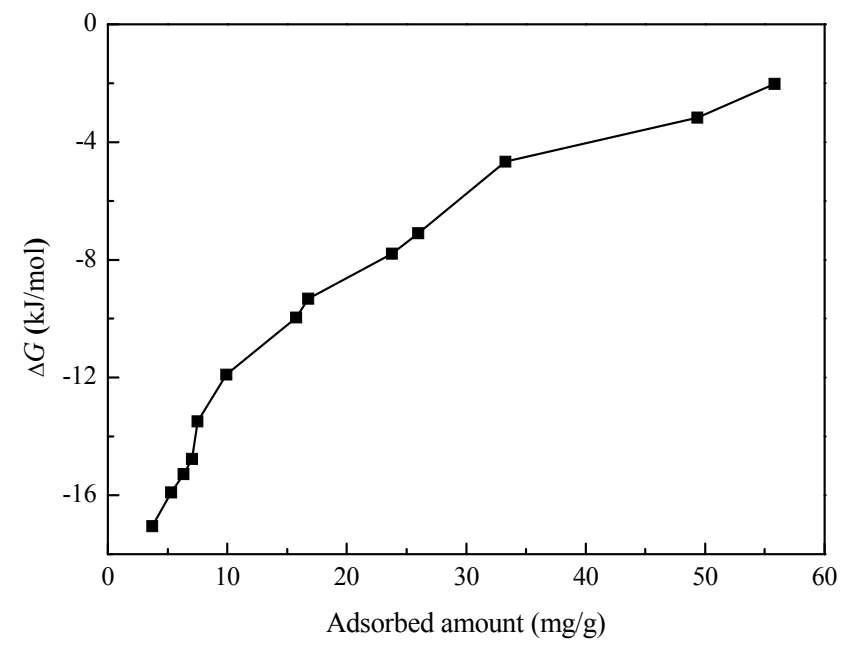

Fig. 10. Free energy $\Delta G$ of toluene adsorption on $\mathrm{Pd} / \mathrm{Gr} / \mathrm{Cor}$ at $40^{\circ} \mathrm{C}$.

$\mathrm{Pd} / \mathrm{Gr} /$ Cor is a process of increasing order degree. Therefore, we can refer that toluene molecule are transferred from the gas phase to the surface of the $\mathrm{Pd} / \mathrm{Gr} /$ Cor catalyst, and most of them are adsorbed to be parallel to the graphene surface due to $\pi-\pi$ conjugation [30-32]. As for toluene, when it was adsorbed on graphene, the motion style changed from disordered three-dimensional motion in gas bulk to the two-dimensional motion on graphene surface[4,5]. Therefore, the order degree increases significantly, as indicated by the reduced entropy [36,37].

It is obvious that the adsorption of toluene on the $\mathrm{Pd} / \mathrm{Gr} /$ Cor catalyst proceed spontaneously. Additionally, the released heat of adsorption for toluene on the $\mathrm{Pd} / \mathrm{Gr} /$ Cor catalyst is large and equivalent to chemical reaction heat. It further indicated that the toluene adsorption on $\mathrm{Pd} / \mathrm{Gr} / \mathrm{Cor}$ is a chemisorption process [35]. Additionally, is negative sign of $\Delta S$ may also be due to the chemisorption [36,37].

The correlation of catalysts' characterizations, activity performance and adsorption simulating reveals that the enhanced activity and stability of the $\mathrm{Pd} / \mathrm{Gr} /$ Cor catalyst for toluene catalytic combustion can be mainly attributed to three aspects.

(i) The total adsorption capacity of toluene on $\mathrm{Pd} / \mathrm{Gr} / \mathrm{Cor}$ is greatly enhanced relative to that on $\mathrm{Pd} / \mathrm{Cor}$. This is mainly attributed to the highly-ordered assembly of toluene molecule on the graphene surface, which greatly increases the local concentration of toluene on the catalyst's surface. This point can be fully proved by the results of the two sites' localized adsorption isotherm model and the value of the adsorption entropy $\Delta S$. The concentration gap between the surface of graphene and Pd provide the driving force for toluene transfer.

(ii) Pd particles have stronger adsorption affinity to toluene than graphene does. This can be revealed by the greater adsorption coefficient of toluene on $\mathrm{Pd}\left(K_{m}\right)$ than that on graphene $\left(K_{a}\right)$. According to Eley-Rideal mechanism [21,22], oxy-

Table 1

Calculation results for the adsorption of toluene on $\mathrm{Pd} / \mathrm{Gr} /$ Cor.

\begin{tabular}{cccc}
\hline$Q_{\mathrm{st}} /(\mathrm{kJ} / \mathrm{mol})$ & $\Delta H /(\mathrm{kJ} / \mathrm{mol})$ & $\Delta G /(\mathrm{kJ} / \mathrm{mol})$ & $\Delta S /(\mathrm{kJ} / \mathrm{mol})$ \\
\hline 91.45 & -91.45 & $<0$ & -0.2633 \\
\hline
\end{tabular}

gen is dissociated on Pd particles to generate activated oxygen and the combustion reaction of toluene happened on the surface of Pd [38]. Except for the concentration gap, the affinity gap between $\mathrm{Pd}$ and graphene provide the second driving force for toluene transfer.

In this sense, graphene supplies a larger adsorption capacity of toluene, and Pd particles exhibit a stronger adsorption affinity to toluene. When toluene is combusted on $\mathrm{Pd}$, graphene could simultaneously and rapidly transfer toluene to Pd particles due to the significant concentration and the affinity gap. Compared with Pd/Cor, it is through the adsorption-catalytic synergistic effect that $\mathrm{Pd} / \mathrm{Gr} /$ Cor delivers enhanced activity.

(iii) The moisture resistance of the catalyst is improved by the graphene coating. Only because the large amount of toluene assembly on the graphene coating during the reaction process, the hydrophobicity of graphene can be maintained. The passive effect of water on the stability of the catalyst is beyond the scope of this paper. Therefore, the Pd/Gr/Cor catalyst delivers significantly improved stability in the moist toluene feed. The schematic diagram of the toluene catalytic combustion on the $\mathrm{Pd} / \mathrm{Gr} /$ Cor catalyst is illustrated in Fig. 11.

\section{Conclusions}

In the present work, the $\mathrm{Pd} / \mathrm{Gr} /$ Cor catalyst exhibited enhanced activity and stability for toluene catalytic combustion in both the dry and moist conditions compared with Pd/Cor without graphene coating. The correlation of catalysts' characterizations, activity performance and adsorption simulation reveals that the total adsorption capacity of toluene on $\mathrm{Pd} / \mathrm{Gr} /$ Cor compared with that on $\mathrm{Pd} /$ Cor was greatly enhanced, due to the highly-ordered assembling of toluene molecule on the graphene surface. This point was fully proved by the results of the two sites' localized adsorption isotherm model and the value of adsorption entropy $\Delta S$. In addition, Pd particles have stronger adsorption affinity to toluene than that of graphene. The significant concentration and affinity gap between graphene and Pd ensures a simultaneously and rapid transfer of toluene during the reaction process. Compared with $\mathrm{Pd} /$ Cor, it is through the adsorption-catalytic synergistic effect that $\mathrm{Pd} / \mathrm{Gr} / \mathrm{Cor}$ delivers an enhanced activity. The large amount of toluene assembly on graphene ensures the hydro-

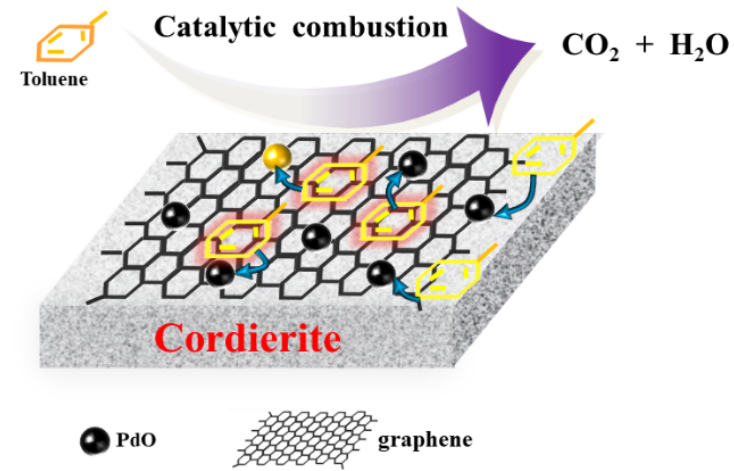

Fig. 11. A schematic diagram of toluene catalytic combustion on the $\mathrm{Pd} / \mathrm{Gr} /$ Cor catalyst. 
phobicity of the support and further eliminates the passive effect of water on stability of catalyst. Therefore, the Pd/Gr/Cor catalyst delivers significantly improved stability in the moist toluene feed.

The kinetics study indicated that the catalytic combustion of toluene on the $\mathrm{Pd} / \mathrm{Gr} /$ Cor catalyst fitted the first-order reaction model well, and the activation energy was $60.93 \mathrm{~kJ} / \mathrm{mol}$. Moreover, the $\mathrm{Pd} / \mathrm{Gr} /$ Cor catalyst has excellent adsorption properties for toluene due to the presence of graphene, and the adsorption for toluene fits the Freundlich model well. The FLm model indicated that the support has a larger adsorbed amount, but the Pd particles have stronger adsorption affinity, so the support could always provide toluene for the Pd particles during the reaction. The strong adsorption plays an important role in improving the performance of the toluene catalytic combustion and interprets the adsorption-catalytic synergistic effect indirectly.

\section{Acknowledgments}

Kai Han is funded by China Postdoctoral Science Foundation (2015M582343, 2016T90758) and Hunan Provincial Natural Science Foundation of China (2017JJ3376).

\section{References}

[1] R. Beauchet, P. Magnoux, J. Mijoin, Catal. Today, 2007, 124, 118-123.

[2] F. Wyrwalski, J. F. Lamonier, S. Siffert, A. Aboukais, Appl. Catal. B, 2007, 70, 393-399.

[3] C. Moreno-Castilla, A. F. Pérez-Cadenas, F. Agustin, Materials, 2010, 3, 1203-1227.

[4] S. Roy, A. K. Heibel, W. Liu, T. Boger, Chem. Eng. Sci., 2004, 59, 957-966.

[5] T. Haakana, E. Kolehmainen, I. Turunen, J. P. Mikkola, T. Salmi, Chem. Eng. Sci., 2004, 59, 5629-5635.

[6] S. Belochapkine, J. Shaw, D. Wenn, J. R. H. Ross, Catal. Today, 2005, 110, 53-57.
[7] H. S. Kim, T. W. Kim, H. L. Koh, S. H. Lee, B. R. Min, Appl. Catal. A, 2005, 280, 125-131.

[8] X. W. Su, L. Y. Jin, J. Q. Lu, M. F. Luo, J. Ind. Eng. Chem., 2009, 15, 683-686.

[9] P. Euzen, J. H. Le. Gal, B. Rebours, Q. Martin, Catal. Today, 1999, 47, 19-27.

[10] K. Persson, L. D. Pfefferle, W. Schwartz, A. Ersson, S. G. Jaeras, Appl. Catal. B, 2007, 74, 242-250.

[11] O. Demoulin, G. Rupprechter, I. Seunier, B. Le Clef, M. Navez, P. Ruiz, J. Phys. Chem. B, 2005, 109, 20454-20462.

[12] E. A. Dawson, P. A. Barnes, M. J. Chinn, Carbon, 2006, 44, 1189-1197.

[13] F. J. Maldonado-Hodar, C. Moreno-Castilla, A. F. Perez-Cadenas, Appl. Catal. B, 2004, 54, 217-224.

[14] M. Q. Zhang, B. Zhou, K. T. Chuang, Appl. Catal. B, 1997, 13, 123-130.

[15] A. K. Geim, Science, 2009, 324, 1530-1534.

[16] Y. Q. Zhou, J. D. Wei, X. M. Wang, H. J. Ni, Y. Zhu, Modern Chem. Ind., 2015, 35, 42-45.

[17] Y. C. Zhu, L. Y. Yu, X. F. Wang, Y. H. Zhou, H. Q. Ye, Catal. Commun., 2013, 40, 98-102.

[18] Y. C. Zhu, Y. H. Zhou, L. Y. Yu, G. G. Liu, Y. X. Tian, H. Q. Ye, RSC Adv., 2014, 4, 9480-9483.

[19] W. Z. Wang, Y. Zhang, Y. B. Wang, J. Chem. Phys., 2014, 140, 094302/1-094302/6.

[20] K. Han, Z. Liu, J. M. Shen, Y. Y. Lin, F. Pai, H. Q. Ye, Adv. Funct. Mater., 2015, 25, 455-463.

[21] N. Burgos, M. Paulis, M. Mirari. Antxustegi, M. Montes, Appl. Catal. $B, 2002,38,251-258$.

[22] F. Wang, J. S. Li, J. F. Yuan, X. Y. Sun, J. Y. Shen, W. Q. Han, L. J. Wang, Catal. Commun., 2011, 12, 1415-1419.

[23] C. He, P. Li, J. Cheng, Z. P. Hao, Z. P. Xu, Water Air Soil Poll. 2010, 209, 365-376.

[24] G. G. Liu, L. Y. Yu, Y. C. Zhu, X. G. Guo, Y. H. Zhou, H. Q. Ye, Chin. J. Catal., 2015, 36, 148-152.

[25] L. H. Dubois, R. G. Nuzzo, J. Am. Chem. Soc., 1983, 105, 365-369.

[26] E. Bus, J. T. Miller, J. A. Van Bokhoven, J. Phys. Chem. B, 2005, 109, 14581-14587.

[27] G. G. Liu, S. Gui, H. Zhou, F. T. Zeng, Y. H. Zhou, H. Q. Ye, Dalton Trans., 2014, 43, 6977-6980.

\section{Graphical Abstract}

Chin. J. Catal., 2018, 39: 946-954 doi: 10.1016/S1872-2067(18)63015-3

The role of graphene coating on cordierite-supported Pd monolithic catalysts for low-temperature combustion of toluene

Wen Li, Hongqi Ye, Gonggang Liu, Hongchao Ji, Yonghua Zhou *, Kai Han*

Central South University

Schematic structure of the $\mathrm{Pd} / \mathrm{Gr} /$ Cor catalyst and tentative processes of the catalytic combustion of toluene over the $\mathrm{Pd} / \mathrm{Gr} / \mathrm{Cor}$ catalyst as illustrated. The graphene coating plays important roles during the catalytic combustion of toluene.

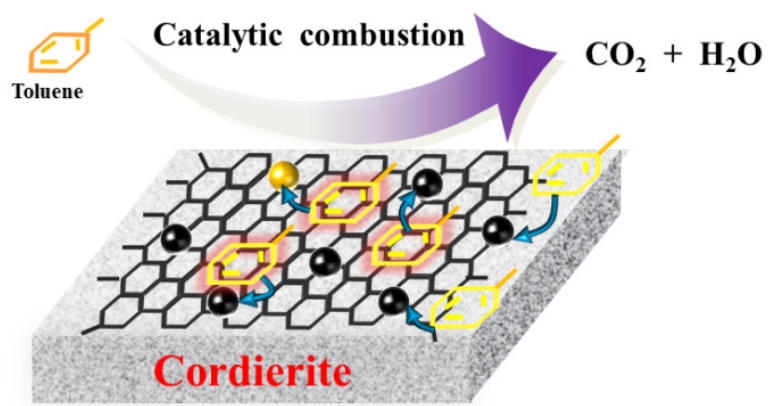

- Pdo 
[28] W. G. Shim, J. W. Lee, S. C. Kim, Appl. Catal. B, 2008, 84, 133-141.

[29] M. Echard, J. Leglise, Thermochimica Acta, 2001, 379, 241-254.

[30] X. Q. Zhang, Y. Y. Feng, S. D. Tang, W. Feng, Carbon, 2009, 48, 211-216.

[31] G. G. Liu, K. Han, H. Q. Ye, C. Y. Zhu, Y. P. Gao, Y. Liu, Y. H. Zhou, Chem. Eng. J., 2017, 320, 74-80.

[32] Z. Liu, J. T. Robinson, X. M. Sun, H. J. Dai, J. Am. Chem. Soc., 2008, 130, 10876-10877.

[33] H. H. Pan, J. A. Ritter, P. B. Balbuena, Langmuir, 1998, 14,
6323-6327.

[34] A. J. Ramirez-Pastor, F. Bulnes, Physica A, 2000, 283, 198-203.

[35] X. Y. Pang, B. Xing, G. C, Wang, M. Yoshitada, N. Junji, ActaPhys. Chim. Sin., 2009, 25, 1352-1356.

[36] B. L. Newalkar, R. V. Jasra, V. Kamath, S. G. T. Bhat, Microporous Mater., 1997, 11, 195-205.

[37] V. R. Choudhary, D. B. Akolekar, A. P. Singh, S. D. Sansare, J. Catal., 1988, 111, 23-40.

[38] R. Imbihl, J. E. Demuth, Surf. Sci., 1986, 173, 395-410.

\title{
石墨烯涂层在甲苯低温催化燃烧用堇青石负载 Pd 整体式催化剂中的作用
}

\author{
李雯, 叶红齐, 刘贡钢, 纪宏超, 周永华*, 韩凯 ${ }^{*}$ \\ 中南大学化学化工学院, 湖南长沙 410083
}

摘要: 对于传统整体催化剂而言, 堇青石等基体比表面积低, 往往需先涂覆活性氧化铝等高比表面涂层, 此外低温催化燃 烧反应生成的水和周围空气中的水分会大量吸附于亲水性氧化物涂层表面, 导致贵金属催化活性降低, 同时, 贵金属的分 散度也是影响催化剂活性的主要因素. 我们利用石墨烯高疏水性、二维平面结构、对苯环强吸附及对贵金属颗粒的高分 散与针定作用等独特性能, 发展基于石墨烯涂层的高活性纳米 $\mathrm{Pd}$ 整体催化剂, 以改善上述问题. 所制备的 $\mathrm{Pd} /$ 石墨烯/堇青 石 $(\mathrm{Pd} / \mathrm{Gr} / \mathrm{Cor})$ 复合材料作为整体催化剂用于甲苯低温燃烧反应, 通过考察催化性能和吸附行为, 重点研究了石墨烯涂层 的作用. 催化性能结果表明, 与无石墨烯涂层的传统 $\mathrm{Pd} / \mathrm{Cor}$ 催化剂相比, $\mathrm{Pd} / \mathrm{Gr} / \mathrm{Cor}$ 催化剂对甲苯的起燃温度从 $175{ }^{\circ} \mathrm{C}$ 降 至 $132{ }^{\circ} \mathrm{C}$, 且在水蒸气存在的情况下表现出更好的稳定性. TEM 和吸水速率表征表明, 石墨烯涂层可显著提高 Pd 纳米粒 子的分散性, 提高堇青石载体的疏水性. 动力学研究表明, $\mathrm{Pd} / \mathrm{Gr} / \mathrm{Cor}$ 催化剂上甲苯催化燃烧符合一级反应动力学规律, 活 化能为 $60.93 \mathrm{~kJ} / \mathrm{mol}$.

此外, 研究了其吸附行为, 包括吸附等温线, 吸附动力学和吸附热力学. 模拟结果表明, Pd/Gr/Cor 催化剂对甲苯具有优 异的吸附性能, 对甲苯的吸附符合 Freundlich 模型, 为化学吸附. FLm 双点位吸附模型表明, 石墨烯表面吸附了大量的甲 苯, 而 Pd 粒子表面吸附的甲苯相对较少, 但亲和力较强. 吸附热力学计算表明, 石墨烯对甲苯的吸附是一个自发的放热反 应, 是一个熵减小的过程, 表明甲苯分子可在石墨烯上高度有序组装. 石墨烯与 Pd 之间的显著浓度差和亲和力的差距确 保了反应过程中甲苯在石墨烯上的快速转移. 吸附动力学研究表明, 催化剂对甲苯的吸附为快速过程, 催化反应为控速步 骤.

综上, 石墨烯涂层不仅可以提高 Pd 纳米粒子的分散性, 提高催化剂的疏水性, 在催化反应过程中, 还可利用其强吸附 能力提高催化剂表面的甲苯浓度, 而显著的浓度差和亲和力的差距可作为驱动力为 $\mathrm{Pd}$ 粒子提供甲苯, 从而发挥吸附-催化 协同作用优势, 进一步提高催化性能.

关键词: 石墨烯涂层; 钯; 催化燃烧; 水蒸气; 吸附

收稿日期: 2017-11-13. 接受日期: 2017-12-20. 出版日期: 2018-05-05.

*通讯联系人. 电话/传真: (0731)88876616; 电子信箱: zhouyonghua@csu.edu.cn

通讯联系人. 电话/传真: (0731)88876616; 电子信箱: hankai@csu.edu.cn 基金来源：国家自然科学基金 (21276284, 21676303,21706292).

本文的电子版全文由Elsevier出版社在ScienceDirect上出版(http://www.sciencedirect.com/science/journal/18722067). 